\title{
Efficiency of nitroglycerine and diltiazem coadministration comparison with topical bethanechol and diltiazem in the treatment of chronic anal
}

\section{fissures: a randomized clinical trial}

Baran Parhizkar ${ }^{1}$, Parviz Esmaeilzadeh², Asrin Babahajian ${ }^{3}$, Houshiyar Ghafory $^{4}, \underline{\text { Amir Hossein }^{2}}$ Entezari $^{5}$

1.Gastroenterologist, Liver and Digestive Research Center, Research Institute for Health Development, Kurdistan University of Medical Sciences, Sanandaj, Iran. ORCID ID: 0000-0003-3043-3504

2.Pharmacist, Liver and Digestive Research Center, Research Institute for Health Development, Kurdistan University of Medical Sciences, Sanandaj, Iran. ORCID ID: 0000-0001-8450-5863

3.Master of Anatomical Science, Liver and Digestive Research Center, Research Institute for Health Development, Kurdistan University of Medical Sciences, Sanandaj, Iran. ORCID ID: 0000-0003-0278-1560

4.Master of Biochemistry Science, Liver and Digestive Research Center, Research Institute for Health Development, Kurdistan University of Medical Sciences, Sanandaj, Iran. ORCID ID: 0000-0002-1466-4161

5.Internal Medicine, Liver and Digestive Research Center, Research Institute for Health Development, Kurdistan University of Medical Sciences, Sanandaj, Iran., (Corresponding Author), Tel: 087-33664658, Email: Amirhosein_entezari@yahoo.com. ORCID ID: 0000-0001-8701-9529

\begin{abstract}
Background and Aim: Anal fissure is one of the common anorectal disorders that there are various therapies for it. The aim of this study is to evaluate the effect of Nitroglycerin plus Diltiazem vs either of topical Diltiazem and Bethanechol alone in the treatment of chronic anal fissure.
\end{abstract}

Materials and Methods: The present randomized double-blind clinical trial was performed on 90 patients with chronic anal fissure referred to gastroenterology clinic of Tohid Hospital, Sanandaj, Iran, from March 2016 to February 2017, That randomly were divided into three equal groups $(\mathrm{n}=30)$ : A: combination therapy ( $1 \%$ Nitroglycerin plus $5 \%$ Diltiazem gel), B: Diltiazem (5\% Diltiazem gel) and C: Bethanechol (0.1\% Bethanechol gel). The drugs were administered topically three times daily for 8 weeks. After 4 and 8 weeks' administration wound condition, pain and bleeding was assessed. Data were analyzed by SPSS v.19 software with Chi-square test.

Results: At the beginning of the study, there was no significant difference in mean of age, sex, fissure location, hemorrhoids, bleeding and pain between the three groups $(\mathrm{P}>0.05)$. Four weeks after treatment, there was no significant difference between the three groups in terms of the Wound healing $(\mathrm{P}=0.41)$, pain $(\mathrm{P}=0.10)$ and bleeding $(\mathrm{P}=0.07)$. After 8 weeks, there was a significant difference for pain in the treatment groups $(\mathrm{P}=0.04)$, so that in the diltiazem group, pain was significantly decreased in comparison to Betanchenol and There was no significant difference between the three groups in the case of Wound healing $(\mathrm{P}=$ $0.10)$ and bleeding $(\mathrm{P}=0.69)$.

Conclusion: Topical use of diltiazem is a more appropriate option for treatment of chronic fissure than other two drugs.

Keywords: Anal fissure, Drug treatment, Nitroglycerine Ointment, Diltiazem gel, bethanechol gel

Received: July 22, $2019 \quad$ Accepted: Oct 3, 2020

\footnotetext{
How to cite the article: Baran Parhizkar, Parviz Esmaeilzadeh, Asrin Babahajian, Houshiyar Ghafory, Amir Hossein Entezari. Efficiency of nitroglycerine and diltiazem coadministration comparison with topical bethanechol and diltiazem in the treatment of chronic anal fissures: a randomized clinical trial.咶SJKU 2021;26(2):25-31.
}

Copyright (C) 2018 the Author (s). Published by Kurdistan University of Medical Sciences. This is an open access article distributed under the terms of the Creative Commons Attribution-Non Commercial License 4.0 (CCBYNC), where it is permissible to download, share, remix, transform, and buildup the work provided it is properly cited. The work cannot be used commercially without permission from the journal 


\section{بررسى اثر تركيب داروىهاى موضعى نيتروتليسرين و ديلتيازيم در مقايسه با دو روش}

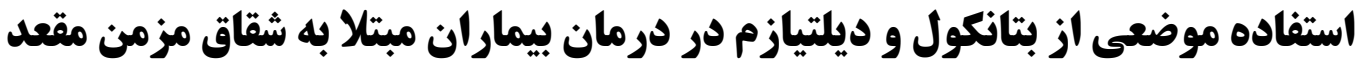

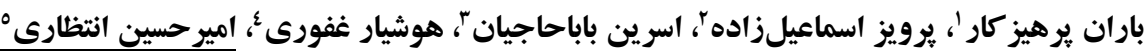

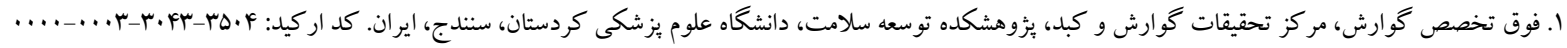

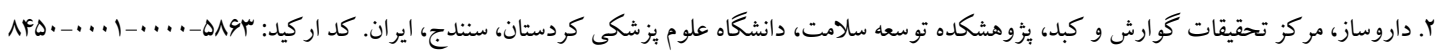

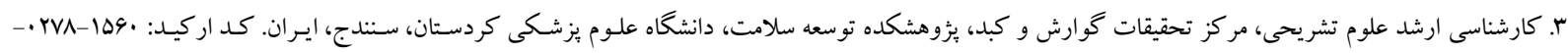

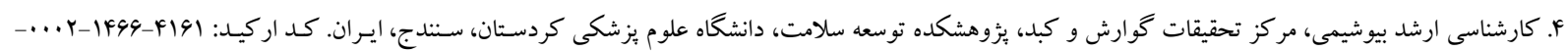

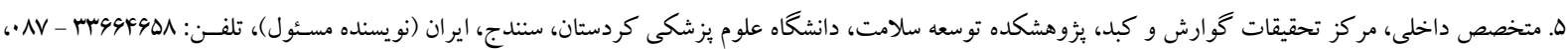

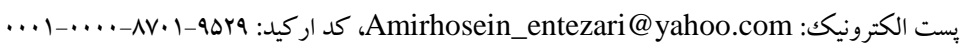
جكيده

زمينه و هدف: شقاق مقعد يكى از بيمارىهاى شايع آنور كتال است و درمانهاى دارويى مختلفى براى آن وجود دارد. هدف از

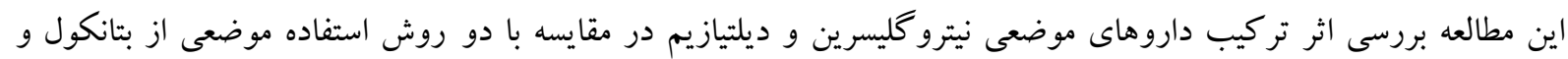

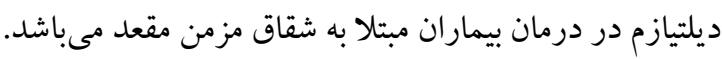
مواد و روشها: مطالعه حاضر به روش كار آزمايى بالينى تصادفىشده دو سو كور بود كه از بين بيماران مبتلا به شقاق مقعد مدان

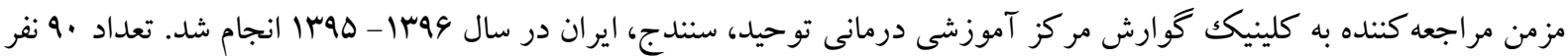

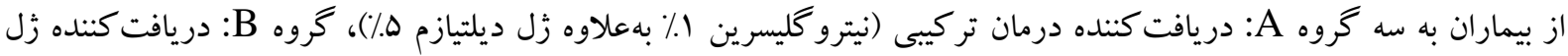

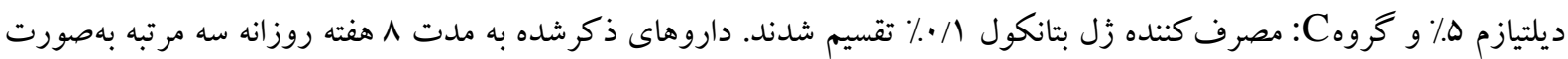

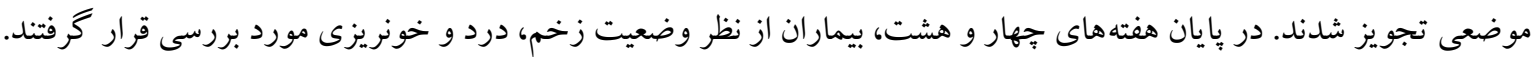

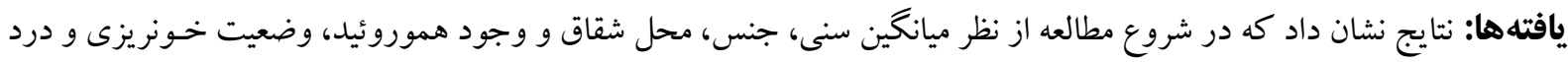

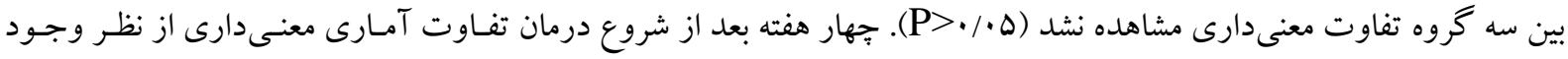
شقاق (Pl/Fl)

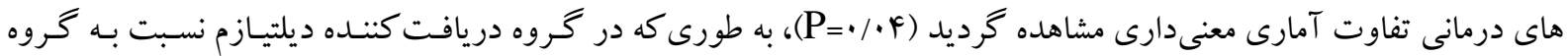

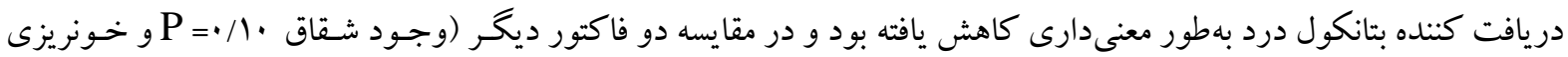
بين سه گروه اختلاف معنى دارى ايجاد نشد.

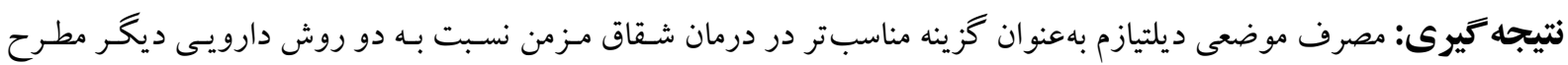
مىباشد. وازههاى كليدى: فيشر آنال، درمان دارويى، بماد نيترو كليسرين، زل ديلتيازيم، زل بتانكول

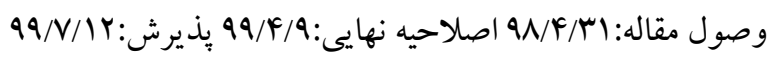


درمان دارويى و جانشين مناسب براى نيترو كليسرين موضعى

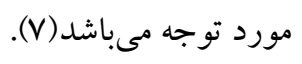

بتانكول يكك آكونيست كولينرزيكى موسكارينى است كه با. اثـرات انقباضسى در عضـلات صـاف (معسدهاى كرودهاى) مى تو اند سبب كاهش فشار در حال استراحت اسفنكتر آنال شود(^). در يكك مطالعه مصرف فرم موضعى بتانكول به طور

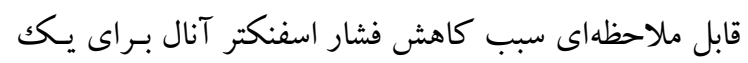

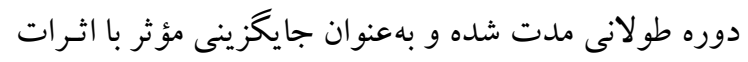
جانبى كمتر بجاى نيتراتهاى موضعى در درمـان فيشرهـاى مونى

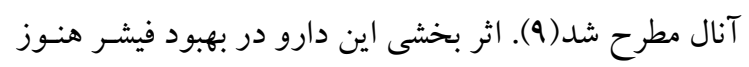

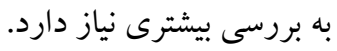

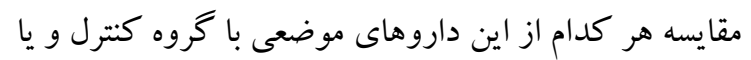

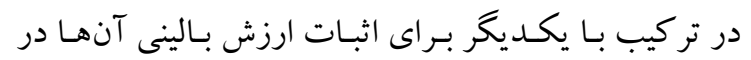

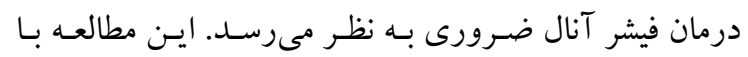
هدف مقايسه سه روش درمـان دارويسى استفاده موضعى از

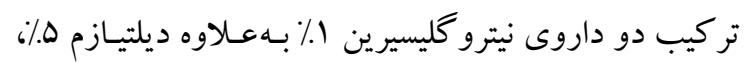

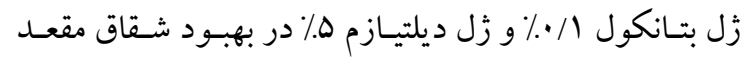

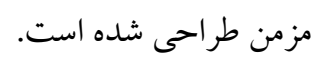

\section{مواد و روشها} طراحى مطالعه:

اين مطالعه كه به صورت كار آزمايى بالينى تصادفى شـده بـا

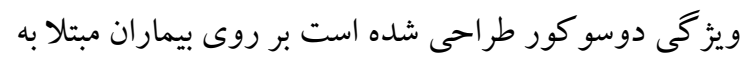

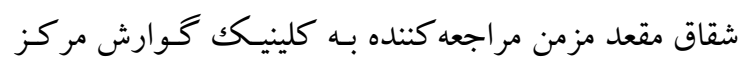

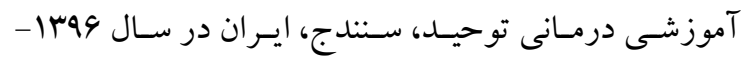

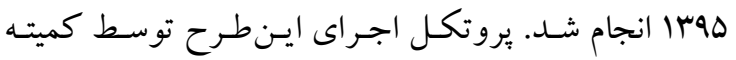

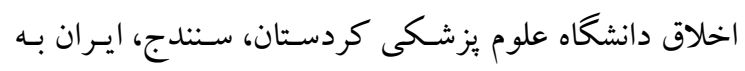
تصويب رسيده (No. IR.MUK.REC1394.142) و نيـز No. ) در بايخاه كار آزمايى بالينى ايران به ثبت رسيده است ونئ (IRCT2016110130623N1

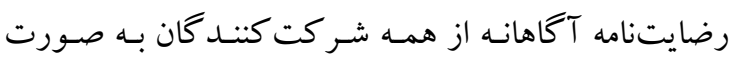
كتبى اخذ شد.
مقدمه شقاق مقعد يكى از بيمارىهـاى شـايع آنور كتـال اسـت كـه

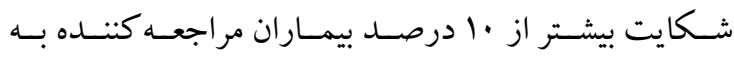
كلينيك هاى برو كتولوزى را شامل مىشود (1) و شامل يـك إنك

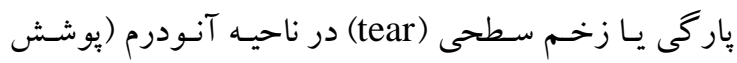

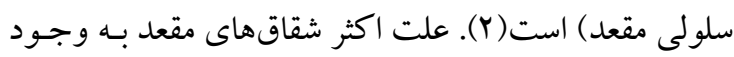

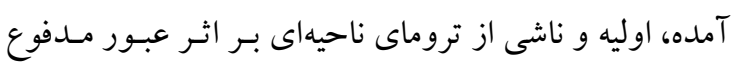

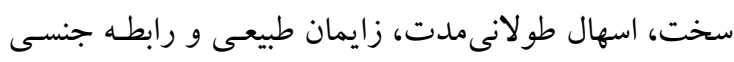

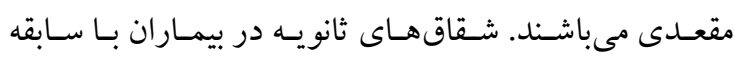
جراحسىهـاى آنـال، ابـتلا بـه بيمـارى هــاى التهـابى روده،

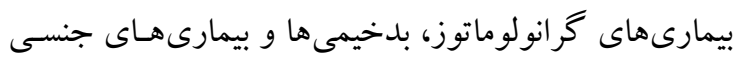

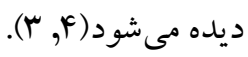

بيماران با شقاق بـهور تيييكك داراى فشـار بـالاى اسفنـكتر

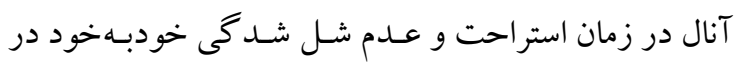

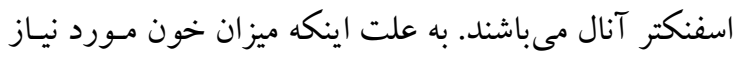
آنودرمال از اسفنكتر داخلى آنال مسى گحذرد ايـن فشـار بـالا

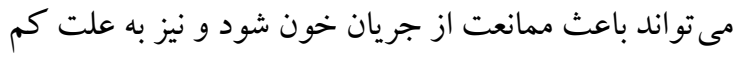

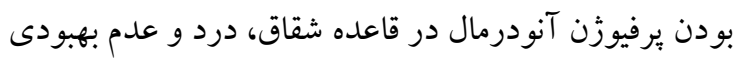

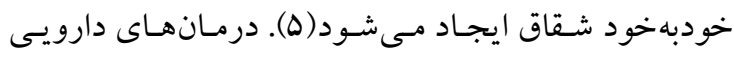

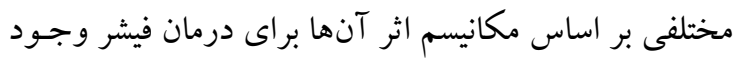

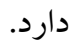
يمـاد نيترو گليسسيرين بـا كـاهش فشـار در حسال اسـتراحت

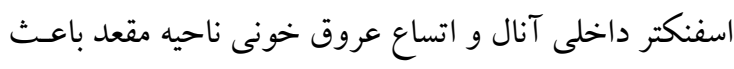
افز ايش خونرسانى به اين ناحيه شـده و در نتيجـه بـه تـرميم

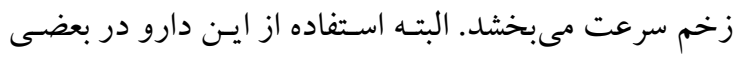
افر اد باعث سوزش در محل استفاده يـا سـردرد مى گحردد (4),

از آنجاكه قسـمت اعظمم انقبـاض اسفنكتر داخلى آنـال بـا حضور يونهاى كلسيم صورت مى گيرد مصرف خوراكى يا

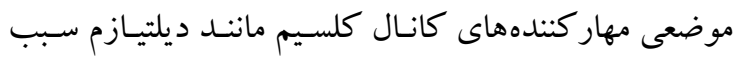

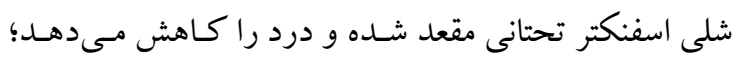

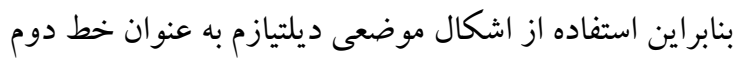


تجزيهو تحليل آمارى با استفاده از نرم افزار SPSS نسخه ب انجام شد. براى تحليل فرضيات جهت نرمال بودن دادههاى Shapiro- و كمى از آزمون Kolmogrov-Smirnove استفاده شد. متغيرهاى كيفى بهصورت فراوانى (درصد)، متغيرهاى كمى با ميانگين (SE) محاسبه شدند. براى مقايسه متغيرهاى كيفى بين گروههاى مطالعه از آزمون Chi-Square سطح معنى دارى در نظر گرفته شد.

\section{يافته ها}

از ارديبهشت هوسا تا فروردين وهسا، تعـداد •ه بيمـار وارد مطالعه شدند و به صورت تصادفى به سه گروه دريافت كننده

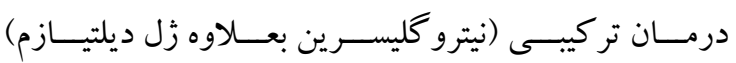

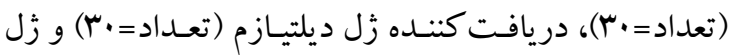
بتانكول (تعـداد=•r) تقسـيم شـدند. تمـام بيمـاران موفـق بـهـ تكميل دوره درمان شدند. نتايج مطالعه حاضر نشـان داد كـه

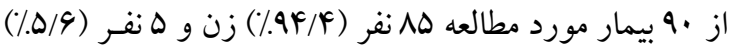

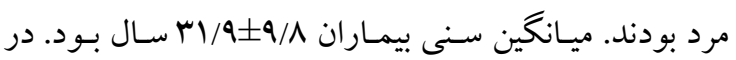
جدول ا خصوصسيات دمو گر افيـك و بـالينى بيمـاران نشـان داده شده است. در شروع مطالعه از نظر وضعيت خونريزى و درد بـين گرووههـا تفـاوت آمـارى معنسىدارى مشـاهده نشـد

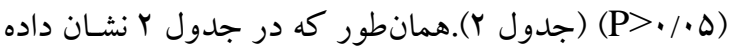
شده است در دومين ويزيــت (جهار هفتـه بعـد از مداخلـه)، تفاوت آمارى معنسىدارى از نظر وجـود شـقاق ( (P=/FI)، درد (•/1/ نشد. در ويزيت سوم (هشت هفته بعد از مداخله) تنها از نظر وجود درد در گرووهاى درمانى تفـاوت آمـارى معنسىدارى

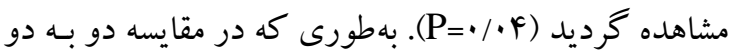
كروهها با هم، دركروه دريافت كننده ديلتيازم نسبت به گروه دريافت كننده بتانكول درد به طور معنى دارى كـاهش يافتـه

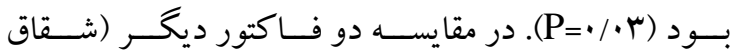

افر اد و اجد شرايط شامل افر اد بالاى ل 1 سال مبـتلا بـه شـقاق مقعـد مـزمن كـه رضـايت آكاهانسه از مشـار كت در طـرح داشتند، بودند. معيارهاى خـروج از مطالعـه شـامل حـاملكى، بيمارى التهابى روده، بـروز عـوارض دارو، تـركك درمـان و بدخيمى روده بود. روش هاى درمانى و مداخله:

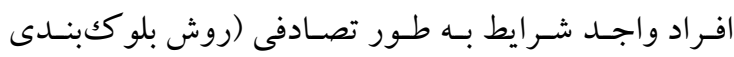
تصادفى جهارتايى) به سـه گ Aروه A: دريافت كنتـده درمـان تر كيبـى (نيترو كليسـرين 1\% بـهـــلاوه زل ديلتيـازم ه.٪ بـهـ صسورت دو محصـول مجـز|)، گـروه B: دريافت كننـده زل

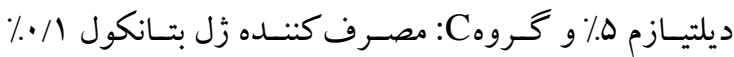
تقسيم شدند. ليست تصـادفى سـازى بـه صـورت كـامِيوترى ايجاد شد و زلهـاى تهيهشـده توسط فردى كـه از ماهيـت مطالعه آكاهى نداشت در جعبههاى مشـابه و شـماره گذارى

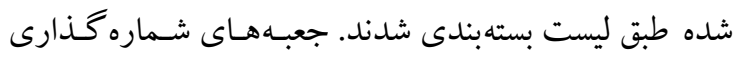
شده محتوى داروها توسط شخص ديخرى كه از توالىهـاى

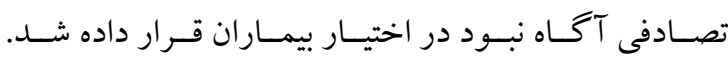
شر كت كنند گان در مطالعه نيز از محتويات جعبهها آكاهى نداشتند.

بـس از انجـام معاينـه فيزيكى توسط يزشـك محـل شـقاق (بر حسب قدامى، خلفى يـا لتـر ال بـودن)، تعـداد شـقاقهـا و حضـور يـا عــدم حضـور همزممـان همورئيسد، وجــود درد، خونريزى و اطلاعات دمو كر افيك آنها ثبت كرديد. به همه بيماران دركنار توصيه هاى غذايى و استفاده از حمـام آب گرم سه بار در روز، زلهاى ذكرشده بـه مـدت م هفتـه روزانه سه مرتبه با حداقل دو ساعت فاصله تجويز شد. علاوه بر آنها يكك داروى مسهل (شربت منيزيم هيدرو كسـايد) و قرص مترونيدازول •له سه بـار در روز بـه مـــت V روز نيـز تجويز گرديـد. در بايـان هفتـهــاى جهـار و هشـت بيمـاران مجدد معاينه و از نظر وضعيت زخم، درد و خـونريزى مـورد

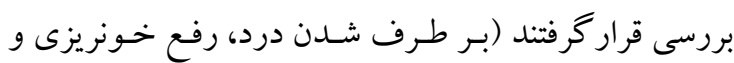
بهبود زخم در معاينه فيزيكى باسخ به درمان تلقى گرديد). 


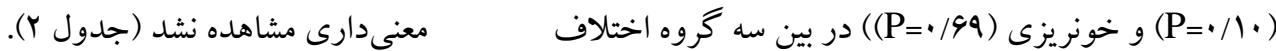
جدول ا. اطلاعات دمو كر افيك و بالينى افر اد مورد مطالعه

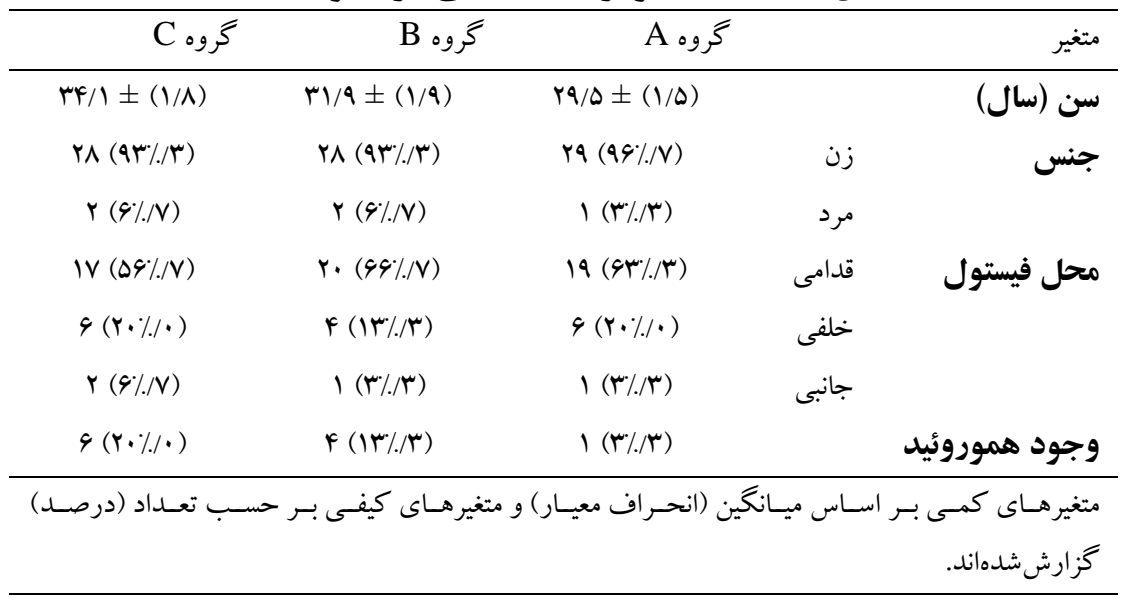

جدول r. علائم و نشانهاى بيمار در طى دوره مداخله

\begin{tabular}{|c|c|c|c|c|c|c|c|}
\hline Pvalue & م هفته بعد از & Pvalue & مد هفته بعد از & Pvalue & شروع مطالعه & كروه & علائم \\
\hline & $\mathbb{T r}(\boldsymbol{\xi} \cdot \%)$ & & $11(9 . \%)$ & & $r \cdot(1 \ldots \%)$ & A & فيشر قابل مشاهده \\
\hline & 1. ( $(\Pi \pi \%)$ & & $19(\Delta r \%)$ & & $r \cdot(1 \ldots \%)$ & B & \\
\hline \multirow[t]{3}{*}{.$/ 1$} & $10(0 \cdot \%)$ & $\cdot / 41$ & $Y(V \cdot \%)$ & & $r \cdot(1 \ldots \%)$ & $\mathrm{C}$ & \\
\hline & $q(r \cdot \%)$ & & $11(r V \%)$ & & r\& $(\Lambda V /)$. & $\mathrm{A}$ & درد \\
\hline & $r(1 . \%)$ & & $V(Y r \%)$ & & Yq $(q \vee \%)$ & B & \\
\hline \multirow[t]{3}{*}{.$/ . F$} & $11(\mathrm{rV} \%)$ &.$八$ & $10(\Delta \cdot \%)$ & r & YA (qY\%) & $\mathrm{C}$ & \\
\hline & $r(V /)$ & & $\wedge(\mathrm{YV} /)$. & & $\mathrm{IV}(\Delta \mathrm{V} /)$. & A & خونزيزى \\
\hline & $r(1 . \%)$ & & $\Delta(\mid \mathrm{V} /)$. & & $19(9 \pi \%)$ & B & \\
\hline .199 & $F(\mid r \%)$ & $\cdot / \cdot V$ & $\mathbb{N}(\boldsymbol{\kappa} \boldsymbol{\kappa} /)$ & $\cdot / 149$ & $r r(V r \%)$ & $\mathrm{C}$ & \\
\hline
\end{tabular}

كرووه تفاوت معنسى دارى بـاهـم نداشـتند. ميـزان بهبـودى در كروه دريافت كننده ديلتيازم موضعى در ويزيت دوم و سـوم به ترتيب FV و FV درصـد، گ Fروه دريافت كنتـده داروهـاى

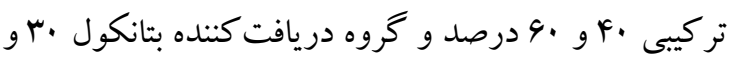
•ه درصد بود كـه نشـان مسىدهـد هر جنــد تفـاوت معنسى دار نبوده؛ ولى ميزان بهبودى در گرووه دريافـت كنتـده ديلتيـازم موضعى بيش از گروه تركيبى و در گرووه تركيبى بـيش از كروه درمانى با بتـانكول بـوده اسـت. در مطالعسه Araujo و و

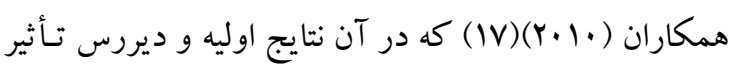
ديلتيازم موضعى و بتانكول بر روى ·9 بيمار مبـتلا بـه شـقاق مقعدى بررسى شده بود ميز ان بهبودى يس از هشت هفته در
در اين مطالعه گروههـاى مـورد بررسىى از نظر ويثز گهى دمو گر افيكك (سن و جنس) و همجينين محل شـقاق، وجـود

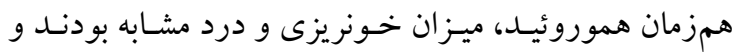
تفاوت معنى دارى بين آنها ديده نشــ (ه •/P> (P). در نتيجـه اين متغيرها نتو انستهاند نتايج مربوط به مداخله را تحت تأثير قـرار دهنــد. در مطالعـات مختلـف نقـش نيترو گليسـرين و ديلتيازم در بهبود فيشر مشخص شده است(19-1.1). در ايسن مطالعه تر كيب آنها نتو انسته نتيجـه بهترى را كسـب نمايسد. نتايج اين مطالعه نشـان داد ميـزان بهبـودى (رفـع شـقاق) در

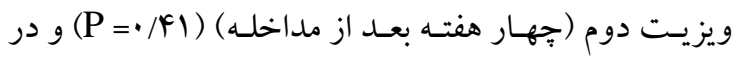

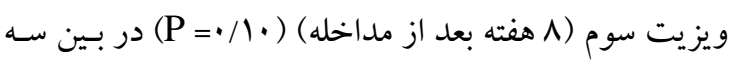


كروه درمانى با بتانكول بَ درصد افر اد خونريزى داشتند كه

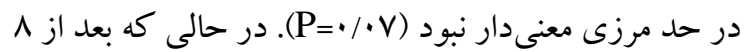
هفتـه ايـن ميزانهـا در كروههـاى دريافت كنتـده ديلتيـازم،

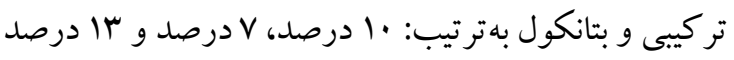
بود كه تفاوت معنىدارى بين آنها وجود نداشت.

\section{نتيجه كيرى}

مطالعه ما نشان داد كه استفاده موضعى از ديلتيازم در كنترل

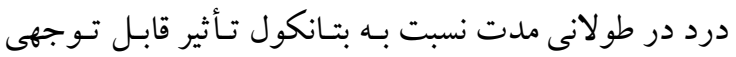
دارد و استفاده همزمـان از نيترو گليسـرين بـهـــلاوه ديلتيـازم شرايط بهترى در بهبـود فيشـر نسبت بـه مصـرف دو داروى

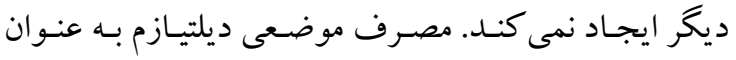

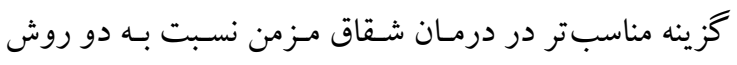
دارويى ديخر مطرح مىباشد.

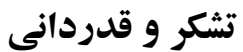

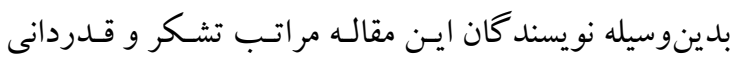
خود را از مركز تحقيقـات كبـد و گـوارش دانشعاه علدوم يزشكى كردستان به دليل همكارى و حمايـتهـاى مالى از

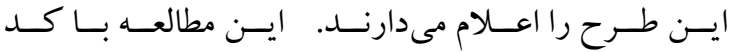
اخلاق IR.MUK.REC.1394.14 ثبـت گرديـده اسـت. هيج كدام از نويسند كان اين مقاله تعارض منافعى براى انتشار

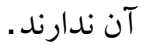

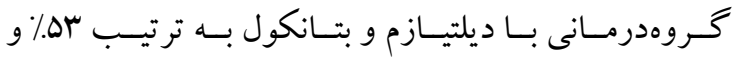

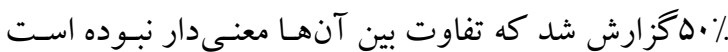

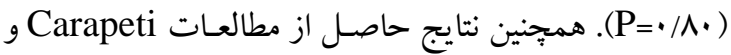

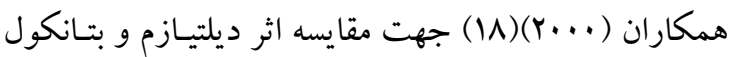

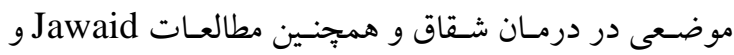

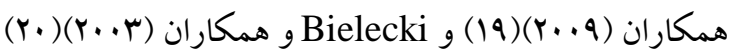

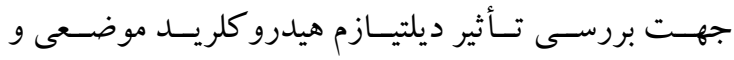

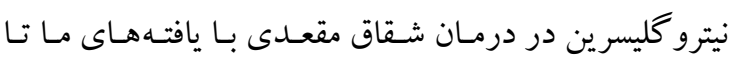
حدود زيادى از نظر معنىدار نبودن تفـاوت بهبودى در بين

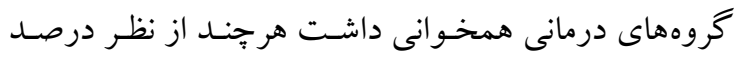

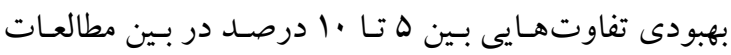
ديده شد. اين تفاوتها مى تواند مربوط به طول دوره مطالعه و همجنين دوز دارو و درصد تركيبات آن باشد.

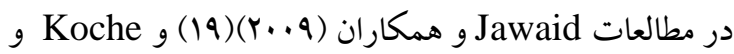

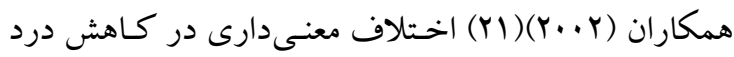
در طى دوره درمان بين دو گرووه دريافـت كنتـده ديلتيـازم و نيترو گليسرين موضعى مشاهده نشد. نتايج مطالعه ما نيز نشان داد هر جند مصرف تنها زل هـ٪ ديلتيازم نسبت بـه استفاده از تر كيب دو دارو در كاهش درد مؤثرتر بوده (بعد از جهار و

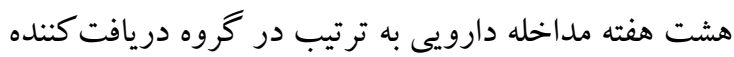

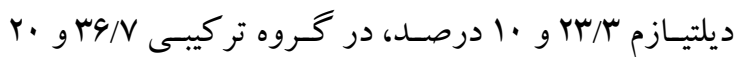
درصد افراد درد داشـتند)؛ امـا ايـن اختـلاف بـين دو گروهـ معنى دار نيست. در مطالعـه مـا بعـد از هشت هفته در گركروه دريافت كننده ديلتيازم نسبت به گروه دريافت كننده بتـانكول درد به طور معنىدارى كاهش يافته بـود. بـراى اثبـات تأثير بيشتر اين دو دارو در كاهش درد، مقايسه دوزهـاى مختلف آنها مى تو اند كمك كننده باشد.

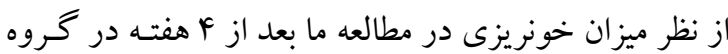

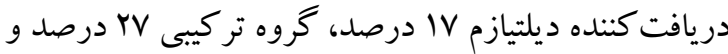

1.Bullard K, Rothenberger D. Colon, Rectum and Anus in: BrunicariaCF, Schwartz principles of surgery. edition t, editor: McGraw-Hill; 2005 
2.Jensen SL. Treatment of first episode of acute anal fissure: Prospective randomized study of lignocaine ointmentversus hydrocortisone ointment or warm sitz baths plus bran. BMJ. 1986; 292: $1167-9$

3.Madalinski $\mathrm{MH}$. Identifying the best therapy for chronic anal fissure. World $\mathrm{J}$ Gastrointest Pharmacol Ther. 2011; 2:9

4.Oh C, Divino CM, Steinhagen RM. Anal fissure 20-year experience. Dis Colon Rectum. 1995; $38: 378$

5.Brisinda G, Maria G, Bentivoglio AR, Cassetta E, Gui D, Albanese A. A comparison of injections of botulinum toxin and topical nitroglycerin ointment for the treatment of chronic anal fissure. $\mathrm{N}$ Engl $\mathbf{J}$ Med. 1999;341(2):65-9

6.McLeod RS, Evans J. Symptomatic care and nitroglycerin in the management of anal fissure. J Gastrointest Surg. 2002;6(3): 80-278.

7.Jonas M, Neal KR, Abercrombie JF, Scholefield JH. A randomized trial of oralvs. topical diltiazem for chronic anal fissures. Dis Colon Rectum. 2001; 44(8):1074-8

8.Steele SR, Madoff RD. Systematic review: the treatment of anal fissure. Aliment Pharmacol Ther. 2006;24(2):247-57

9.Carapeti EA, Kamm MA, Evans BK, Phillips RK. Topical diltiazem and bethanechol decrease anal sphincter pressure without side effects. Gut.1999; 45: 719-22

10.Lund JN, Scholefield JH. A randomized, prospective, double-blind, placebo-controlled trial of glyceryl trinitrate ointment in treatment of anal fissure. Lancet. 1997; 349:11-14

11.Kennedy ML, Sowter S, Nguyen H, Lubowski DZ. Glycery trinitrate ointment in the treatment of chronic anal fissure: results of a placebo-controlled trial and long term follow-up. Dis Colon Rectum.1999;42:100-106

12.Altomare DF, Rinaldi M, Milito G, Arcanà F, Spinelli F, Nardelli N, et al. Glyceryl trinitrate for chronic anal fissure - healing or headaches? Results of a multicentre, randomized, placebo-controlled, double-blind trial. Dis Colon Rectum. 2000; 43(2):174-181

13.Werre AJ, Palamba HW, Bilgen EJ, Eggink WF. Isosorbide dinitrate in the treatment of anal fissure: a randomized, prospective, double-blind, placebo-controlled trial. Eur J Surg. 2001; 167:382385

14.Tankova L, Yoncheva K, Muhtarov M, Kadyan H, Draganov V.Topical mononitrate treatment in patients with anal fissure. Aliment Pharmacol Ther. 2002; 16:101-103

15. DasGupta R, Franklin I, Pitt I, Dawson PM. Successful treatment of chronic anal fissure with diltiazem gel. Colorectal Dis. 2002; 4:20-22

16.Knight JS, Birks M, Farouk R. Topical diltiazem ointment in the treatment of chronic anal fissure. Br J Surg. 2001; 88:553-556

17.Araujo SE, Sousa MM, Caravatto PP, Habr-Gamai A, Cecconello I. Early and late results of topical diltiazem and bethanechol for chronic anal fissure: a comparative study. Hepatogastroenterology. 2010;57(97):81-5

18.Carapeti EA, Kamm MA, Phillips RK. Topical diltiazem and bethanechol decrease anal sphincter pressure and heal anal fissures without side effects. Dis Colon Rectum. 2000;43(10):1359-62

19.Jawaid M, Masood Z, Salim M. Topical diltiazem hydrochloride and glyceryl trinitrate in the treatment of chronic anal fissure. J Coll Physicians Surg Pak. 2009;19(10):614-7

20.Bielecki K, Kolodziejczak M. A prospective randomized trial of diltiazem and glyceryltrinitrate ointment in the treatment of chronic anal fissure. Colorectal Dis. 2003;5(3):256-7

21.Kocher HM, Steward M, Leather AJ, Cullen PT. Randomized clinical trial assessing the sideeffects of glyceryl trinitrate and diltiazem hydrochloride in the treatment of chronic anal fissure. $\mathrm{Br} \mathrm{J}$ Surg. 2002;89(4):413-7 